\title{
Öğretmen Adaylarında Bilişsel Farkındalık Düzeyleri, Öznel Mutluluk ve Sıkıntıyı Tolere Etme Arasındaki Yordayııı İlişkiler ${ }^{1}$
}

\author{
DOI: 10.26466/opus.520293 \\ * \\ Bülent Dilmaç $-\underline{\text { Mustafa Yilmaz }}$ \\ * Prof. Dr., Necmettin Erbakan Üni., Ahmet Keleşoğlu Eğitim Fak. Meram / Konya/ Türkiye \\ E-Posta: bulentdilmac@gmail.com \\ ORCID: $\underline{0000-0001-5753-9355}$ \\ ** Psik. Dan., İTO İbrahim Çağlar Anadolu İmam Hatip Lisesi, İstanbul/Türkiye \\ E-Posta: mustafayilmaz001@yandex.com \\ ORCID: $\underline{0000-0003-1437-2430}$
}

$\ddot{O} z$

Bu çalışmanın amacı, öğretmen adaylarında bilişsel farkındalık düzeyleri, öznel mutluluk ve sıkıntıyı tolere etme arasındaki yordayıcı ilişkileri incelemektir. Araştırmada, öğretmen adaylarında bilişsel farkındalık, sıkıntıyı tolere etme ve öznel mutluluk arasındaki ilişkilerin belirlenmesi ve bu değişkenler arasındaki ilişkilerin yapısal eşitlik modeli ile sınanması amacıyla yapısal eşitlik modellemesi analizi yapılmıştır. Ölçekler, 2017-2018 eğitim öğretim döneminde İstanbul'da çeşitli üniversitelerde öğrenim gören öğretmen adaylarından oluşmaktadır. 529 katılımonın 139'u erkek 390'ı kadın katılımoıdır. Araştırmadan elde edilen bulgulara göre; öğretmen adaylarının bilişsel farkındalık düzeyleri ile sıkıntıyı tolere etme düzeyleri arasındaki yordayıcı ilişkiler incelendiğinde, bilişsel farkındalı̆̆ın sıkıntıyı tolere etmeyi yordadı̆̆ı, aradaki ilişkinin pozitif yönlü ve doğrusal olduğu bulunmuştur. Öğretmen adaylarının sıkıntıyı tolere etme düzeyleri ile öznel mutluluk düzeyleri arasındaki yordayıcı ilişkiler incelendiğinde, sıkıntıyı tolere etmenin öznel mutluluğu yordadığı, aralarındaki ilişkinin pozitif yönlü ve doğrusal olduğu bulunmuştur. Öğretmen adaylarının bilişsel farkındalı düzeyleri ile öznel mutluluk düzeyleri arasındaki yordayıcı ilişkiler incelendiğinde bilişsel farkındalı̆̆ın öznel mutluluğu yordadığı, aralarındaki ilişkinin pozitif yönlü ve doğrusal olduğu bulunmuştur.

Anahtar Kelimeler: Bilişsel Farkındalık, Biliş Ötesi, Mutluluk, Öznel Mutluluk, Sıkıntıyı Tolere Etme, Üst Biliş

\footnotetext{
${ }^{1}$ Bu makale Mustafa YILMAZ'ın Yüksek Lisans tezinin bir bölümünden hazırlanmıştır.
} 


\title{
The Predictive Relationship Between Cognitive Awareness Levels Subjective Happiness Distress Tolerance in Teacher Condidates
}

\begin{abstract}
The aim of this study is to examine the predictive relationships among cognitive awareness levels, subjective happiness and distress tolerance teacher candidates. In the study, a structural equation modeling analysis was carried out in order to determine the relations between cognitive awareness, distress tolerance and subjective happiness in teacher candidates and the structural equality model of relations among these variables. The scales are composed of prospective teachers from various universities in Istanbul during the 2017-2018 education period. Of the 529 participants, 139 are male and 390 are female participants. According to the findings obtained from the research; when the predictive relationships between the levels of cognitive awareness of the prospective teachers and the levels of distress tolerance were examined, it was seen that there was a positive linear relationship. When the predictive relationships between the levels of distress tolerance of teacher candidates and subjective happiness levels are examined, it is seen that there is a positive linear relationship. When the predictive relationships between the levels of cognitive awareness and subjective happiness of teacher candidates are examined, it is seen that there is a positive linear relationship.
\end{abstract}

Keywords: Cognitive Awareness, Beyond Cognition, Happiness, Subjective Happiness, Distress Tolerance, Upper Cognition 


\section{Giriş}

Yaşanan duygular her an yaşam durumlarını, bireylerin algılarını, tepkilerini, düşünce ve davranışlarını etkileyen bir sistemdir (Ceylan, 2012). Duygu durumumuz değişkenlik gösterebilen yapıdadır. Kendimizi nasıl hissettiğimiz var olan durumun yapısına bağlıdır. Bu değişkenlik yanında diğerlerinden ayırıcı özelliğimiz olarak duygu kalıplarımız mevcuttur (Burger, 2006). Duygular kişiliğin üç boyutundan biridir. Duygular kişiliğin diğer iki boyutu olan davranış ve düşünceleri etkiler. Çeşitli duygu tanımlarında ortak nokta bireyin iç dünyasındaki yaşayış ve algılamalardır. Duyguların bileşenleri; davranış, subjektif hisler ve psikolojik tepkilerdir. Duygulara verilen tepkilerde bireysel sorumluluk vardır. Duygular konusunda farkındalık kazanma, duyguları tanıma ve duyguların sorumluluğunu alma ile gerçekleşebilir (Abacı, 2010b). Duyguların niteliğini belirlemede bilişsel değerlendirmeler önemlidir. Aynı durum için iki farklı kişi farklı bilişsel değerlendirmelerde bulunabilir ve biri için durum mutluluk verici iken diğer için aynı durum üzüntü ve sıkıntıya yol açabilir (Atkinson, Atkinson, Smith, Bem ve Nolen-Hoeksema, 2010).

Aynı durum karşısında farklı duygulara sahip olabilen bireyler yaşadıkları duyguların yönetiminin nasıl olacağı ve diğerlerinin duygu yönetimini nasıl yaptıklarını merak ederler. Duygu düzenlemesinde amaç zararlı duyguları yönetmek, yararlı olanları ise artırmaktır (Gross, 2013). S1kıntıyı tolere etme duygu düzenlemesi içerisinde kabul edilmiştir (Amstadter vd., 2012). Olumsuz psikolojik durumlara dayanma kapasitesidir. Bilişsel ya da fiziksel durumların sonucu olabilir fakat bir duygu durum olarak kendini göstermektedir (Simons ve Gaher, 2005). Duygularımızın işlevi organizmada yaşanan zorlanmalarla başa çıkabilmek için özel bir durum yaratmaktır (Nesse, 2000).

Yaşam deneyimlerini etkileyen ve onlardan etkilenen bir duygu olan mutlulukla ilgili filozoflar duygularını tanımaya yönelen ve bireysel sorumluluğu alan bireyler için mutluluğun ulaşılması gereken ana hedef olduğunu belirtmiş, var olmanın sebebinin mutluluk olduğunu savunmuşlardır (Shin ve Johnson, 1978). Veenhoven (1994)'teki çalışmasında da mutluluğun batı kültüründe ulaşılmak istenen ana hedef olduğunu söylemiştir. Bireyler mutluluğa ulaşmaya çalışırken, toplum önderlerinde de 
mutluluğu vaat edenlere destek vardır. Psikoloji alanında yapılan ilk çalışmalardan 1980'li yıllara kadar pozitif durumlardan daha çok, kaygı, depresyon gibi olumsuz durumların üzerinde araştırmalar yapılmıştır. 1980 sonrası pozitif psikoloji araştırmalarında yaşam doyumu, memnuniyet, mutluluk gibi kavramlara ilgi daha fazla artmıştır. Herkesin belli düzeyde mutlu olduğu fakat bazı bireylerin diğerlerine oranla daha mutlu olduklarını bildirmeleri konusunda, mutluluğun çeşitli değişkenlere göre değişip değişmediği araştırma konusu olmuştur (Myers ve Diener, 1995; Shin ve Johnson, 1978). Pozitif psikoloji memnuniyet, yaşam doyumu, mutluluk gibi konuları ele alırken yaşamdaki sıkıntıları, olumsuz yönleri inkar etmez. Olumsuz yanları kabul etmekle beraber, amacı olumlu duygular ve nihai hedef olan mutluluk konusunda bireye gelişim yolları sunmaktır (Gable ve Haidt, 2005).

Bireyin olumlu, olumsuz duygularını anlayabilmesi, yaşam olaylarını anlamlandırması için kendisi ve çevresi hakkında farkındalığı önemlidir (Girgin, 2012). Farkında olmama duygu düzenlemede sıkıntılar yaşanmasina neden olur (Vatan, 2016). Mutluluk için, kişinin kendisi hakkındaki bilişsel farkındalığı denilebilir. Ortaya konan kuramlarda bilişsel farkındalıkta mutluluk sorumluluğu bireye verilmiştir. Farkındalıkla beraber birey yaşamın her anının farkında olur ve bu durum bireyin yaşamdan aldığgı doyumu, mutluluğunu artırıcı bir yoldur (Özen, 2017). Bireyler yaşam boyunca olumsuz birçok duygu yaşarlar. Önemli olan bunlarla baş etme ve duyguda herhangi bir zarar görmeden üstesinden gelmektir. Bunun için bireyler kendilerine karşı şefkat göstermelidir. Çünkü şefkat farkındalık sahibi olmayı ve kendine karşı önyargısızlık, açıklık ve nezaket göstererek de iyi olma (mutluluk) haline sahip olmayı içerir (Deniz, Kesici ve Sümer, 2008). Bilinçli bireylerin yetiştirilmesinde farkındalık önemli olmakta, farkındalıkla birlikte düşünme yetenekleri ve bunlara bağlı olarak öğrenme ve başarı düzeyleri de artmış olacaktır (Doğan, 2013). Bilişsel farkındalık, bireyin görev ve buna dönük strateji hakkında farkındalık geliştirmek için yansıtıcı düşünme becerisini kullanabilmesidir. Bilişsel farkındalığın geliştirilmesi bireylerin karar verme süreçlerinde daha etkin olmalarını sağlar (Ridley, Schutz, Glanz ve Weinstein, 1992). Bilişsel farkındalık, öz düzenlemeye dayalı bir düşünce sistematiğidir. Üst düzey öğrenmelerde etkin olarak kullanılan bilişsel farkındalık, analiz, sentez, değer- 
lendirme basamaklarında kazanımlar oluşturur ve öğrenmenin her adıminda yer alır (Demir ve Doğanay, 2010). Bilişüstü bilgi ve yordamsal bilgiyi içeren bilişsel farındalıkta bilişüstü bilgi; bilişsel şemalar, stratejiler ve bireylerin sahip olduğu bilgilerdir (Aktamış ve Uça, 2010). Bilişsel farkındalık dinamik bir süreçtir. Yapılan rutin iş dışında ve daha zor olarak algılanan etkinliklerde çalıştırılır (Wilson, 2001).

Bireyler yaptıkları etkinlikleri nihai amaç olan mutluluğa ulaşmak üzerine şekillendirmektedirler. İçinde bulunulan durumdan hep daha mutlu olabileceğimiz ve mutsuz olmayı kabul etmememiz ortak toplumsal görüş olarak ortaya çıkmaktadır. Hümanistik görüşleri temel alarak yapılan bilimsel çalışmalar yoluyla yapılacak toplumsal reformlar sonucunda daha mutlu bireyler ve daha iyi bir toplum beklentisi mevcuttur. Mutluluk diş kaynaklardan daha çok iç dinamiklerle ilgilidir. Bazen sıkıntılı algılanan bir durumun tolere edilmesi, yaşanılan hoş bir durumdan daha mutluluk verici olabilmektedir (Veenhoven, 1994). Filozoflar tarih boyunca mutluluğa önem vermiş, pozitif psikologlar mutluluk üzerine araştırmalar yapmış olsalar dahi yapılan ağırlıklı çalışmalar sıkıntılar ve bireyin mutsuzluğu üzerinedir (Diener, 1984). Yirminci yüzyılda ve sonrasında yapılan çalışmalarda da ağırlığın psikolojik sıkıntılara verilmesi gelişen tarihi olaylar ve bu olaylardan çıkarılabilecek faydalar olarak görülmüştür (Gable ve Haidt, 2005). Sıkıntı insan yaşamının doğal parçasıdır ve önemli olan sıkıntı ile karşılaşıldığında kaçmak ya da yok saymak değil, işlevsel tolere etme yöntemlerini kullanmaktır (Saulsman ve Nathan, 2012). Yaşanan sıkıntının tolere edilmesi, algılanan ya da gerçek bir sıkıntı durumuyla karşılaşmasına rağmen bireyin hedefine ulaşmak için davranışlarını devam ettirmedeki kararlılığıdır (Brown, Lejuez, Kahler, Strong ve Zvolensky, 2005). Bu kararlılıkta bireysel farklllıklar önemlidir. Bundan dolayı sıkıntıyı tolere etme bilişsel, duyuşsal ve davranışsal özellikleri kapsayan bir yapıdadır (Zvolensky, Leyro, Bernstein ve Vujanovic, 2011). Bilişsel boyutta bilişlerin bilinmesi ve bilişlerin düzenlenmesi şeklinde ortaya çıkar (Schraw ve Moshman, 1995). Bilişsel farkındalığın iki ana öğesi olan biliş bilgisi ve düzenlemesinin temel alındığı becerilerin öğretilmesi, bireyin stres ve endişe kaynaklı otomatik olumsuz duygularını azaltır. Bireylere farkındalık becerilerinin öğretilmesi ile karşılaşabilecekleri zorluklar için yararlı olabilecek problem çözme bilgisi verilmiş olur ve bireylerin 
sıkıntıyı tolere etme becerileri merak ve kabul sayesinde güçlenir ve sıkıntıyı tolere etme kapasiteleri artar (Broderick ve Frank, 2014). Diğer yandan farkındalık sıkıntıları ortadan kaldırmaz ve farkında olmak kaçınmayı engelleyerek sıkıntıyı artırabilir. Fakat farkındalıkla beraber birey geniş açıdan değerlendirme yaparak duyguları düzenleme yeteneğini artırıp, sıkıntıyı daha hızlı şekilde iyileştirebilir (Roemer ve Orsillo, 2003). Böylece farkındalık becerileri olumsuz duyguların kabul edilebilir yüzü olurken (Wachs ve Cordova, 2007), sıkıntıya dayanma gücü de mutluluğun göstergelerinden biri olmaktadır (Oturakçı, 2012).

Kendilerini mutlu hisseden bireyler değişimlere ayak uydurabilir ve kimlik kazanımlarını sağlıklı şekilde gerçekleştirebilirler (Alisinanoğlu, 2002). Çalışma grubunu oluşturan öğretmen adaylarının yaklaşık gelişim dönemleri geç ergenlik ya da genç yetişkinlik dönemidir. Bu dönem yaşamda yetişkinlik konularına geçişi içerir (Burger, 2006). Toplumsal varlık olmanın getirdiği sorumlulukların alındığı bu dönemde, düşünce sistemindeki gelişmişlik ile simgesel boyut önem kazanır. Tutarlı benlik sistemi, gerilime karşı etkin yüceltme mekanizması, yaşamsal sıkıntılara karşı güçlü güvenlik sistemi oluşturulur (Geçtan, 2002). Dostluk, sevgi ve cinsiyet ilişkileri öne çıkar. Dönemin gereğini sağlayamayan bireyler, duygusal soyutlanma yaşarlar (Abacı, 2010a). Bu dönemde bireyden beklenen kendi yaşam amaçlarını ve değerlerini oturtmuş olması ve çevre ile bütünleşirken, kendi benliğinin farkında olması, yani bir kimlik kazanmasıdır (Yörükoğlu, 1990). Tüm yaşamı etkileyecek kararların sorumluluğunun bu dönemde birey tarafından alınması ve kendi kararlarını kendi veriyor olması dönemsel en belirgin sıkıntılardır (Atak ve Çok, 2010).

$\mathrm{Bu}$ araştırmanın ana problemi; öğretmen adaylarında bilişsel farkındalık düzeyleri, öznel mutluluk ve sıkıntıyı tolere etme arasındaki yordayıcı ilişkilerin var olup olmadığını ortaya koyarak, aralarında ilişki varsa bu ilişkinin düzeyi ve ilişki yönünü belirlemektir. Bu kavramların farklı değişkenlerle incelendiği çalışmalar mevcuttur. Ulaşılan çalışmalarda üç kavramın birlikte incelendiği herhangi bir araştırmaya rastlanmamıştır. Değişkenlerle ilgili yurt içi ve yurt dışında yapılan akademik çalışmaların incelenmesi için kavramlarla doğrudan ya da dolaylı olabilecek çalışmalar taranmıştır. Ana amaç çerçevesinde şu sorulara cevap aranmıştır:

1. Öğretmen adaylarının bilişsel farkındalık düzeyleri öznel mutluluklarını yordamakta midır? 
2. Öğretmen adaylarının bilişsel farkındalık düzeyleri sıkıntıyı tolere etmelerini yordamakta midır?

3. Öğretmen adaylarının sıkıntıyı tolere etmeleri öznel mutluluklarını yordamakta midır?

Ülkemizde yapılan araştırmalarda mutlulukla ya da bilişsel farkındalıkla ilgili birçok araştırma mevcut olmasına rağmen sıkıntıyı tolere etme ile ilgili az sayıda çalışma yapılmıştır. Yapılan araştırmanın bu anlamda literatüre katkı sağlayacağı düşünülmektedir.Yapılan araştırmayla öğretmen adaylarında incelenen değişkenlerden alınacak veriler ve değişkenlerin arasındaki ilişkinin belirlenmesi ile durum tespiti yapılmış olacağı ve öğretmen yetiştirme konusunda olası araştırmalar ortaya çıabileceği düşünülmektedir. Bu araştırmanın daha önce hiç yapılmamış olması, literatüre katkı sağlaması açısından önemli olacaktır.

\section{Yöntem}

Bu bölümde araştırma modeli, çalışma grubu, veri toplama araçları, verilerin toplanması ve verilerin nasıl analiz edildiği konusunda bilgilere yer verilecektir.

\section{Araştırma Modeli}

Nicel araştırma paradigmasına sahip bu çalışmada, öğretmen adayların bilişsel farkındalık düzeyleri, sıkıntıyı tolere etme ve öznel mutluluk arasındaki ilişkilerin belirlenmesi ve bu değişkenler aralarındaki ilişkilerin yapısal eşitlik modeli ile sınanması amaçlanmıştır. Bu amaç doğrultusunda araştırma, genel tarama modelinin bir alt türü olan ilişkisel tarama modeline göre gerçekleştirilmiştir.

Genel tarama modelleri, çok sayıda elemandan oluşan bir evrende, evrenin tamamı ya da evrenden alınacak bir grup örnek ya da örneklem üzerinde, evren hakkında genel bir yargıya ulaşmak amacıyla yapılan tarama araştırmalarıdır. Genel tarama modelleri tekil ya da ilişkisel taramalar yapmaya imkân verir (Karasar, 2015). İlişkisel tarama modelleri, iki ya da daha fazla sayıdaki değişken arasındaki değişimin birlikte var olup olmadığını veya bu değişimin derecesini belirlemeyi amaçlayan araştırma modelleridir (Karasar, 2015). 


\section{Çalışma Grubu}

Araştırmanın çalışma grubunu İstanbul ilinde farklı üniversitelerde öğrenim gören 390'1 kadın, 139'u erkek toplam 529 (Tablo-1) öğretmen adaylarından oluşmaktadır. Tablo-1'de görüldügü gibi araştırma katılımclarının 390'i (\%73.7) kadın 153'ü (\%26.3) erkektir.

Tablo 1. Katılımcıların Cinsiyete Göre Dağılımı

\begin{tabular}{lll}
\hline Cinsiyet & Frekans & Yüzde \\
\hline Kadın & 390 & 73.7 \\
Erkek & 139 & 26.3 \\
Toplam & 529 & 100 \\
\hline
\end{tabular}

Tablo-2'de görüldüğü gibi araştırma katılımcılarının 83'ü (\%15.7) birinci sınıf, 129'u (\%24.4) ikinci sinıf, 134'ü (\%25.3) üçüncü sınıf, 18'ü (\%34.6) eğitim fakültesi dördüncü sınıf öğrencisidir.

Tablo 2. Katılımcıların Sınıf Düzeyine Göre Dă̆ılımı

\begin{tabular}{lll}
\hline Sınıf Düzeyi & Frekans & Yüzde \\
\hline 1. Sınıf & 83 & 15.7 \\
2. Sınıf & 129 & 24.4 \\
3. Sınıf & 134 & 25.3 \\
4. Sınıf & 183 & 34.6 \\
Toplam & 529 & 100 \\
\hline
\end{tabular}

Tablo-3' de görüldügüü gibi araştırma katılımcılarının 16'sı (\%3.0) düşük (0-49), 249'u (\%47.1) orta (50-74), 264'ü (\%49.9) yüksek (75-100) akademik başarı düzeyine sahiptir.

Tablo 3. Katılımcıların Akademik Başarı Düzeyi

\begin{tabular}{lll}
\hline Sınıf Düzeyi & Frekans & Yüzde \\
\hline Düşük (0-49) & 16 & 3.0 \\
Orta (50-74) & 249 & 47.1 \\
Yüksek (75-100) & 264 & 49.9 \\
Toplam & 529 & 100 \\
\hline
\end{tabular}




\section{Veri Toplamada Kullanılan Ölçme Araçları}

Bu araştırmada veri toplama aracı olarak Üst Biliş Ölçeği (ÜBÖ), Sıkıntıyı Tolere Etme Ölçeği (STEÖ) ve Öznel Mutluluk Ölçeği (ÖMÖ) kullanılmıştır. Ayrıca katılımcıların demografik özelliklerini belirlemek amacıyla kişisel bilgi formu kullanılmıştır. Araştırmada kullanılan veri toplama araçları hakkındaki tanıtıcı bilgiler aşağıda verilmiştir.

Kişisel Bilgi Formu: Katılımcıların cinsiyet, eğitim durumu, sınıf düzeyi, akademik başarı düzeyi, çalışma hakkındaki bilgileri toplamak amacıyla araştırmacı tarafından hazırlanan kişisel bilgi formu kullanılmıştır.

Üst Biliş Ölçeği-30 (ÜBÖ-30): Üst Biliş Ölçeği-30'daki her madde, 4'lü likert tipi bir ölçeklendirmeye dayanır. Ölçekteki seçenekler "(1) kesinlikle katılmıorum", “(2) kismen katılmıyorum", “(3) kısmen katılıyorum”, “(4) kesinlikle katılıyorum" şeklinde sıralanmıştır. Ölçekten alınabilecek puanlar 30 ile 120 arasında değişir ve puanın yükselmesi patolojik tarzda üst bilişsel faaliyetin arttığına işaret eder. Wells ve Cartwright-Hatton'nın (2004) yaptıkları psikometrik çalışmaya göre, ÜBÖ-30'daki maddeler beş faktöre dağılmaktadır ve bu dağılım uzun formdakiyle özdeştir.

(1) 1, 7, 10, 20, 23 ve 28. maddelerden oluşan olumlu inançlar alt ölçeği, problem çözme ve plan yapmaya yardımcı olarak endişelenmenin kullanılabileceğini ve endişeye yönelik olumlu inançları belirtir. Bu alt ölçeğe göre endişe kişilik özelliği olarak arzu edilir niteliktedir.

(2) 6 , 13, 15, 21, 25, 27. maddelerden oluşan kontrol edilemezlik alt ölçeği ve tehlike alt ölçeğidir. Kontrol edilemezlik alt ölçeği kişinin işlevsel ve güvende olabilmesi için endişelerini kontrol etmesi gerektiği inancl, tehlike alt ölçeği ise endişenin kontrol edilemeyeceği inancıdır.

(3) $8,14,18,24,26$ ve 29. maddelerinden oluşan bilişsel güven alt ölçeği, bireyin bellek ve dikkatine dair güveninin olmaması durumudur.

(4) 2, 4, 9, 11, 16, 22. maddelerden oluşan düşünceleri kontrol ihtiyac1 alt ölçeği, batıl inançlar, cezalandırılma ve sorumlu olma durumları ile ilgili negatif inançları kontrol altına almayı içermektedir. Bu inançlar, kontrol edilmediği durumlarda ortaya çıabilecek olumsuz ve zarar verici sonuçlardan bireyin kendisinin sorumlu olup cezalandırılacağı ile ilişkilidir. 
(5) 3, 5, 12, 17, 19 ve 30. maddelerden oluşan bilişsel farkındalık alt ölçeği, bireyin kendi zihinsel süreçleri üzerinde sürekli performans harcamasını ifade etmektedir.

Ölçeğin Türkçeye uyarlaması Tosun ve Irak (2008) tarafından yapılmıştır. Test tekrar test yöntemi kullanılarak yapılan güvenirlik çalışmasında Türkiye örneklemi için ölçeğin güvenirliğinin yeterli olduğu belirlenmiştir. Ölçeğin iç geçerlik katsayısının yüksek olduğu ve maddeler arası seçici ve anlamlı korelasyonlar olduğu belirlenmiştir. Faktör analizi sonuçları, ÜBÖ-30 Türkçe formunun orijinal formdakiyle aynı faktör yapısına sahip olduğunu göstermiştir.

Sıkıntıyı Tolere Etme Ölçeği (STEÖ): Sıkıntıyı tolere etme ölçeği (STEÖ) Simons ve Gaher (2005) tarafından oluşturulan öz bildirime dayalı 15 maddelik bir ölçektir. Türkçe'ye uyarlaması Akın, Akça ve Gülşen (2015) tarafından yapılmıştır. Ölçekteki ifadeler; Tamamen katılıyorum (1), Katıliyorum (2), Kararsızım (3), Katılmiyorum (4) ve Tamamen katılmıyorum (5) şeklinde sıralandırılan 5'li likert tipi bir ölçeklendirmeye sahiptir.

STEÖ'nün yapı geçerliği için uygulanan doğrulayıcı faktör analizi sonucunda dayanıklılık, yoğunlaşma, değerlendirme ve düzenlemeden oluşan dört alt boyut ve 15 maddeden oluşan modelin iyi uyum verdiği bulunmuştur $\left(x^{2}=316.43\right.$, sd=84, RMSEA=.071, NFI=.94, CFI=.95, IFI=.95, $\mathrm{RFI}=.92$, GFI=.93 SRMR=.053). STEÖ'de maddelerin faktörle ilişkisi .27 ile .72 arasında değişmektedir. Ölçeğin alt boyutlarındaki maddelerin genel uyumu ölçeğin bütünü için .82; alt boyutlarda, dayanıklılık için .62, yoğunlaşma için .66, değerlendirme için .71 ve düzenleme alt ölçeği .61 olarak tespit edilmiştir. Aynı gruba belli aralıklarla uygulanan ölçeğin uygulamaları arasındaki korelasyon ölçeğin tamamı için .63, alt ölçeklerden dayanıklılık için .60, yoğunlaşma için .62, değerlendirme için .64 ve düzenleme alt ölçeği için .58 olarak bulunmuştur. Her boyutun kendi toplam puanının kullanıldığı düzeltilmiş madde toplam korelasyonları .25 ile .59 arasında sıralanmıştır.

Öznel Mutluluk Ölçeği (ÖMÖ): Öznel mutluluk ölçeği (ÖMÖ) Lyubomirsky ve Lepper (1999) tarafından oluşturulan öz bildirime dayalı, 4 
maddeden oluşan, 7'li likert tipi, tek boyutlu ölçektir. ÖMÖ'nün Türkçe'ye uyarlaması Doğan ve Totan (2013) tarafından yapılmıştır. Ölçeğin faktör yükleri .30- .78 arasında ve tek boyutlu yapının varyansın\% 53.94'ünü açıkladığı, toplum grubunun madde faktörü yüklerinin ise; .33.91 arası ve tek boyutlu yapı, varyansın\% 57,20'sini açıklamaktadır. Özgün ölçeğin tek boyutlu olduğu ve faktör analizlerinin sadece bir faktörle sinırlı olduğu göz önünde bulundurulmuştur. Elde edilen sonuçlara göre, örneklem yeterlik katsayısının Kaiser-Mayer Olkin ölçüsü .634 olarak belirlenmiştir ve Barlett'in küresellik testi, üniversite mezunu olan grup için $\chi 2=352.54(\mathrm{df}=6, \mathrm{p}=.000)$ olarak belirlenmiştir. Kaiser-Mayer Olkin'in örneklem yeterlilik katsayısı ölçütleri .674, Barlett'in küresellik testi ise üniversite olmayanlardan oluşan grup için $\chi 2=301.51(\mathrm{df}=6, \mathrm{p}=.000)$ olarak belirlenmiştir. Ölçeğin iç tutarlılık katsayısı diğer toplumlarda elde edilen değerler kadar yüksek olmasa bile kabul edilebilir düzeyde olduğu belirlenmiştir.

\section{Verilerin Toplanmasi}

Ölçekler, uygun örnekleme yöntemi ile tespit edilen katılımcılara araştırmacı ve araştırmanın yardımcıları tarafından uygulanmıştır. Ölçekler İstanbul'da çeşitli üniversitelerde öğrenim gören öğretmen adaylarından oluşmaktadır. Ölçekler uygulanmadan önce katılımcılara araştırmanın amacı ve ölçeğin nasıl uygulanacağı hakkında bilgiler verilmiştir. Ölçeklerin uygulanmasında gönüllülük ilkesi esas alınmıştır. Toplamda 580'i bulan veri sayısı, geçersiz sayılan verilerden dolayı (eksik işaretleme, yarım bırakma, soruları anlayamama... vb.) 529'a düşmüştür. Uygulamalar yaklaşık 20-30 dakika sürmüştür.

\section{Verilerin Analizi}

Araştırmada, öğretmen adaylarında bilişsel farkındalık, sıkıntıyı tolere etme ve öznel mutluluk arasındaki ilişkilerin belirlenmesi ve bu değişkenler aralarındaki ilişkilerin yapısal eşitlik modeli ile sınanması amacıyla karmaşık modellerin test edilmesinde başarılı olan yöntem olduğu için yapısal eşitlik modellemesi kullanılmıştır. Yapısal eşitlik modellemesi incelenen modeldeki ilişkiler arasındaki aracılık ve düzenlemecilik 
etkisini incelemeyi kolaylaştıran, birçok teorinin aynı anda test edilmesinde ve yeni model geliştirmede kullanılan yöntemdir (Schumacker ve Lomax, 2004). Yapısal eşitlik modellemesi analizi AMOS 19 Programı ile gerçekleştirilmiştir. Ayrıca toplanan verilerin yüzde ve frekans hesapları SPSS 18 paket programı ile gerçekleştirilmiştir.

\section{Bulgular}

Ortaya çikan son modellemede $\left(\mathrm{X}^{2}=173.291, \mathrm{df}=57, \mathrm{p}<.001\right)$ beş dışsal değişken, bilişsel farkındalık (olumlu inançlar, kontrol edilemezlik, bilişsel güven, düşünceleri kontrol ihtiyacı, bilişsel farkındalık) beş içsel değişken (dayanıklık, yoğunlaşma, değerlendirme, düzenleme ve öznel mutluluk) veri yer almaktadır. Modelde gösterilen yolların her biri istatistiksel olarak anlamlı bulunmuştur. The Bentler-Bonettnormed fit index (NFI- kurallaştırılmış uyum indeksi), Tucker Lewis Index (TLI), Root Mean Square Error of Approximation (RMSEA- Tahmin hatalarının karekökü), Goodness of Fit Index (GFI- iyilik uyum indeksi), Comparative Fit Index (CFI- kıyaslamalı uyum indeksi), Adjustment Goodness of Fit Index (AGFI- düzeltilmiş iyilik uyum indeksi), modellemenin uyumunun yüksek olduğunu göstermiştir (Tablo-4). Modellemede bulunan içsel değişken dataları arasındaki iki yönlü ilişkinin her biri yüksek dereceye sahiptir ve istatistiksel olarak anlamlıdır. Bu durum, çalışmada kullanılan sıkıntıyı tolere etmenin dayanıklılık, yoğunlaşma, değerlendirme ve düzenleme boyutlarının kendi sahip olduğu bağlılaşım değerlerinden de etkilenmektedir.

Tablo 4. Yapısal Eşitlik Modelinin Uyumu İçin İstatistiksel Değerler

\begin{tabular}{llll}
\hline Ölçüm & İyi Uyum & $\begin{array}{l}\text { Kabul Edilebilir } \\
\text { Uyum }\end{array}$ & $\begin{array}{l}\text { Modelin Uyum İn- } \\
\text { deksi Değerleri }\end{array}$ \\
\hline (X2/sd) & $\leq 3$ & $\leq 4-5$ & 3.5 \\
RMSEA & $\leq 0.05$ & $0.06-0.08$ & .07 \\
SRMR & $\leq 0.05$ & $0.06-0.08$ & .05 \\
NFI & $\geq 0.95$ & $0.94-0.90$ & .94 \\
CFI & $\geq 0.97$ & $\geq 0.95$ & .95 \\
GFI & $\geq 0.90$ & $0.89-0.85$ & .96 \\
AGFI & $\geq 0.90$ & $0.89-0.85$ & .93 \\
TLI & $\geq 0.95$ & $0.94-0.90$ & .92 \\
\hline
\end{tabular}


Tablo-4'te yer alan uyum değerleri incelendiğinde, $\mathrm{X}^{2} / \mathrm{sd}=3.05$, RMSEA $=0.07$, SRMR $=0.050, \mathrm{NFI}=0.94, \mathrm{CFI}=0.95, \mathrm{GFI}=0.96$, AGFI $=0.93$ ve $T L I=0.92$, olarak görülmektedir. Genel itibariyle, modellemenin uyum değerlerinin istendik düzeyde olduğu belirlenmiştir (Browne ve Cudeck, 1993; Bollen, 1989; Hu ve Bentler, 1999; Kline, 2011; Tanaka ve Huba, 1985; Byrne, 2010). Test edilen tek faktörlü model Şekil-1'de görülmektedir. Modellemede var olan tüm yollar 0.01 düzeyinde anlamlidir.

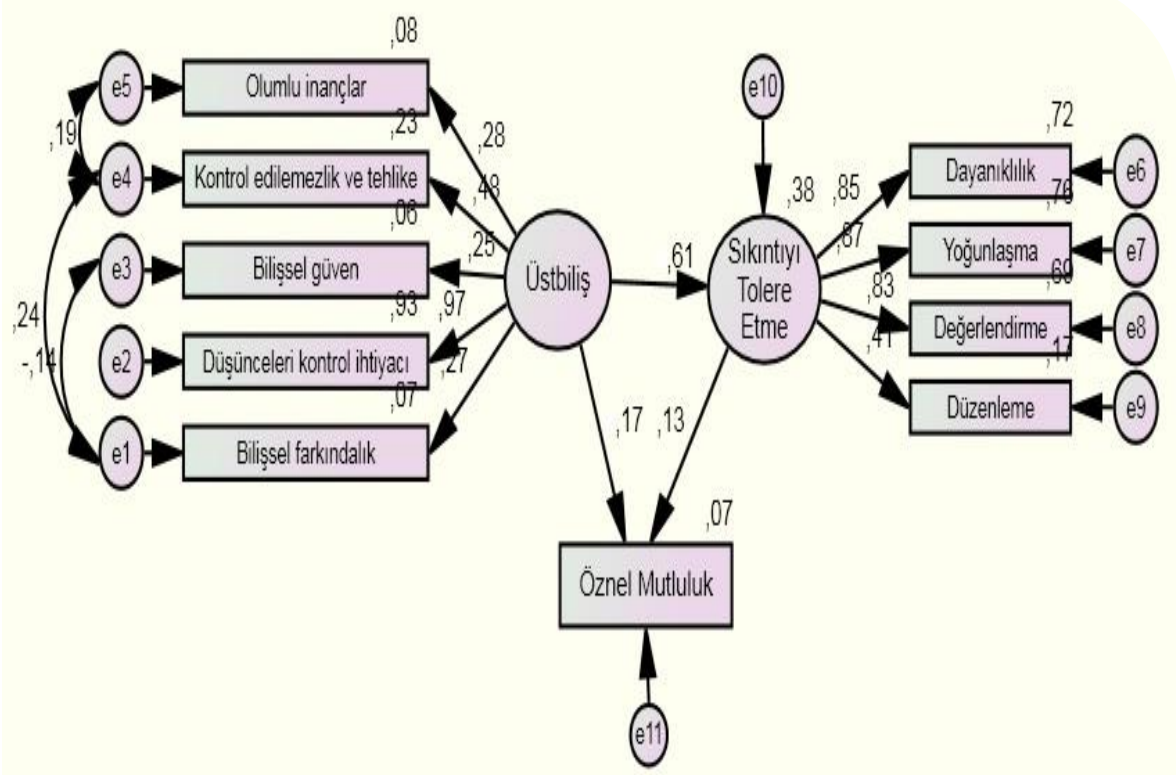

Şekil-1: Modellemeye Dair Yol Değerleri

Tablo 5. Öğretmen adaylarmm sahip olduğu bilişsel farkındalık düzeyleri, sıkıntıyı tolere etme ve öznel mutluluk arasındaki yordayıcı ilişkilere ilişkin modelleme

\begin{tabular}{lllllll}
\hline $\begin{array}{l}\text { Yordayıc1 } \\
\text { Değişken }\end{array}$ & Bağımlı & $\begin{array}{l}\text { Toplam } \\
\text { Değişken }\end{array}$ & $\begin{array}{l}\text { Etki } \\
\text { Etki }\end{array}$ & $\begin{array}{l}\text { Dolaylı } \\
\text { Etki }\end{array}$ & $\begin{array}{l}\text { Standart } \\
\text { Hata }\end{array}$ & $\begin{array}{l}\text { Kritik } \\
\text { Değer }\end{array}$ \\
\hline BF & STE & .61 & .61 & 0 & 0.30 & $5.67^{*}$ \\
BF & ÖM & .16 & .16 & 0 & 0.25 & $2.63^{*}$ \\
STE & ÖM & .25 & .17 & .08 & 0.08 & $2.23^{*}$ \\
\hline
\end{tabular}

${ }^{a}$ Toplam etki $=$ Doğrudan etki + Dolaylı etki, ${ }^{*} p<0.01,{ }^{* *} p<0.05$. 
Tablo-5'e bakıldığında, sıkıntıyı tolere etmeyi (STE) etkileyen önemli bağımsız değişkenlerden biri $(t=-5.67, p<0.01)$ bilişsel farkındalık (BF) değişkenidir. Bu etkene dair bağlantı katsayı değeri $\beta=0.61$ olarak bulunmuştur.

Öğretmen adaylarının bilişsel farkındalık düzeyleri ile sıkıntıyı tolere etme düzeyleri arasındaki yordayıcı ilişkiler incelendiğinde, aynı yönlü doğrusal korelasyon olduğu görülmektedir. Diğer bir şekilde ifade edersek araştırma sonucunda ortaya çıkan bulgularda, öğretmen adaylarının bilişsel farkındalık düzeylerinin artmasıyla sıkıntıyı tolere etme düzeylerinde de artış olacağı ortaya konmuştur.

Öğretmen adaylarında öznel mutluluğu (ÖM) tahmin eden önemli değişkenin $(t=-2.23, p<0.01)$ sıkıntıyı tolere etme (STE) olduğu belirlenmiştir. Bu faktöre ilişkin bağlantı katsayı değerinin $\beta=0.25$ olduğu görülmektedir. Öğretmen adaylarının sıkıntıyı tolere etme düzeyleri ile öznel mutluluk düzeyleri arasındaki yordayıcı ilişkiler incelendiğinde aynı yönlü doğrusal bir korelasyon olduğu görülmektedir. Diğer bir şekilde ifade edersek araştırma sonucunda ortaya çıkan bulgularda, öğretmen adaylarının sıkıntıyı tolere etme düzeyleri arttıkça öznel mutluluk düzeylerinin de artacağını ortaya koymaktadır.

Öğretmen adaylarında öznel mutluluğu (ÖM) etkileyen ikinci bir değişken $(t=-2.63, p<0.01)$ bilişsel farkındalıktır (BF). Bu faktöre ilişkin bağlantı katsayı değerinin $\beta=0.16$ olduğu görülmektedir. Öğretmen adaylarının bilişsel farkındalık düzeyleri ile öznel mutluluk düzeyleri arasındaki yordayıcı ilişkiler incelendiğinde aynı yönlü doğrusal bir korelasyon olduğu görülmektedir. Diğer bir şekilde ifade edersek araştırma sonucunda ortaya çıkan bulgularda, öğretmen adaylarının bilişsel farkındalık düzeyleri arttıkça öznel mutluluk düzeylerinin de artacağını ortaya koymaktadır.

\section{Tartışma}

Bu bölümde araştırmanın çalışma grubunu oluşturan öğretmen adaylarında bilişsel farkındalık düzeyleri, sıkıntıyı tolere etme ve öznel mutluluk arasındaki yordayıcı ilişkilerin incelenmesi sonucu ortaya çıkan bulgular diğer araştırmalarla birlikte tartışılmış ve yorumlanmıştır.

Araştırma sonucunda ortaya çıkan bulgularda; 
Öğretmen adaylarının bilişsel farkındalık ile sıkıntıyı tolere etme düzeyleri arasındaki ilişkiye bakıldığında sıkıntıyı tolere etmeyi etkileyen en önemli bağımsız değişkenin bilişsel farkındalık olduğu ve aralarında pozitif yönlü doğrusal ilişki bulunduğu belirlenmiştir. Öğretmen adaylarının bilişsel farkındalık düzeyleri arttıkça sıkıntıyı tolere etme düzeylerinin artacağı ortaya konmuştur. Sıkıntıyı tolere etme göreve yönelik devamlılık ve kararlılığı içermektedir (Daughters vd., 2017). Bu doğrultuda bilişsel farkındalığı yüksek birey de yaşam amaçları belirleme ve bu amaçlara ulaşmadaki zorlukları aşma becerisine sahip bireydir (Özen, 2017). Sıkıntıyı tolere etme duygu düzenlemesi içerisinde kabul edilirken (Amstadter vd., 2012), bilişsel farkındalı̆̆ın duygusal dengeyi kurmayı ve problemlere sağlıklı çözümler sunmayı içerdiği; bu sayede düşünsel ve duygusal düzenlemede iyi olmayı sağladığı belirtilmiştir (Hayes ve Feldman, 2004). Yani yüksek farkındalık olumsuz duygu ve yaşantılara karşı toleransı sağlamaktadır (Çatak ve Ögel, 2010). Sıkıntıları tolere etmede bireyler öğrenilmiş güçlülük yoluyla düşünce ve davranış düzenlemesi yaparak bilişsel beceriler kullanır (Dağ, 1991). Düşünceyi düzenleme ve denetleme gücü bireyin öğrenmelerinde yapmak istediği faaliyetlerin geçtiğ $i$ süreçler hakkında planlama, değerlendirme, süreçte oluşan sıkıntıları çözme becerisi göstermeden (Demir ve Kaya, 2015) yararlanılarak eğitim, öğretim ortamlarında bilişsel farkındalık becerileri, öğrenmeyi ve öğrenme yollarını daha etkin kılmak için kullanılmaktadır. Birçok gelişimsel becerinin hedeflendiği eğitim ortamlarında kullanılan bilişsel farkındalık stratejileri şu şekildedir: 1. Planlama, 2. Soru üretme, 3. Bilinçli seçme, 4. Birden fazla ölçütle değerlendirme, 5. Kredi alma, 6. "Yapamam" 1 yasaklama, 7. Öğrencilerin fikirlerini geri yansıtan sözler söyleme, 8. Davranışları etiketlemek, 9. Öğrenci terminolojisini açıklamak, 10. Rol oynama ve simülasyonlar, 11. Günlük tutma ve yazmadır (Costa, 1984). Bu araştırmanın sonuçlarından farklı sonuç bulunan araştırmaya göre bireylerin düşünmeleri hakkında düşünme olan bilişsel farkındalıkta düşüncelerinin sorumluluğunun aşırı yüklenilmesi ile düşüncelerin olumsuz yorumlanması sonucu daha fazla sıkıntı yaşayabilmektedirler (Mohammadkhani, 2013). Araştırma sonuçlarını destekleyen yarı deneysel çalışmada ise, s1kıntıyı tolere etme düzeyi düşük olan ergen bireyler belirlenerek bu bireylere bilişsel farkındalık terapisi yapılmış, bulunan sonuçlara göre bilişsel 
farkındalık eğitimi alan bireylerin sıkıntıyı tolere etme düzeyleri yükselmiştir (Azari, Khademi ve Esmali, 2013). Yeme bozukluğu olan bireyler üzerinde yapılan araştırmaya göre, duyguları konusunda olumsuz bilişsel farkındalığa sahip olan bireylerin sıkıntı verici duygu durumları ile baş edemeyecekleri ve bunun kontrol edilemez olduğu düşüncesine sahip oldukları, güçlü olumsuz duyguları tanımlamakta zorlandıkları, olumsuz düşüncelerinin tamamını anormal, kötü ve yanlış olarak etiketledikleri belirlenmiştir. Bu durumda olan bireylerin zihin oyalaması (dikkat dağıtma), bastırma-kaçınma, olumsuz düşüncelerin sürekli incelenmesi ve sosyal çekilme gibi işlevsel olmayan baş etme yollarına başvurdukları belirlenmiştir. Bilişsel farkındalık terapisi yoluyla düşüncelerin sağlıklı yorumlanması ve kabulü, işlevsel olmayan başa çıkma yollarının işlevsel olanlarla değiştirilmesi sağlanmış olacak ve sıkıntı olarak algılanan durumlarla baş etmede etkin yollar bulunabileceği belirtilmiştir (Vann, Strodl ve Anderson, 2013).

Araştırmanın bir diğer bulgusuna göre öznel mutluluğu etkileyen diğer değişkenin bilişsel farkındalık olduğu, iki değişken arasında pozitif yönlü doğrusal ilişki olduğu yani öğretmen adaylarının bilişsel farkındalık düzeyleri arttığında öznel mutluluk düzeylerinin de artacağı ortaya konmuştur. Felsefi, dini ve psikolojik gelenekler mutluluğun sağlanmasında farkındalığın önemini vurgulamışlardır (Brown ve Ryan, 2003). Özen' in (2017) yaptığ 1 araştırmaya göre bilişsel farkındalık ile mutluluğun iç içe bir ilişkide olduğu, bilişsel farkındalığın mutluluğu ve duygusal esnekliği geliştirdiği, öznel iyi oluşun ise bireyin kendisi ve çevresine karşı farkındalık ve duyarlılık olduğu, bireyin yaşadı̆̆ı başarısızlık ya da olumsuz yaşantılara karşı farkındalık içerisinde olması ve kendisine özen göstermesi olduğu belirtilmektedir. Buradaki en önemli nokta bilişsel farkındalıkla birlikte mutluluğa ulaşma sorumluluğu bireyin kendisine verilmiştir. Öznel mutluluğu yüksek birey yaşamındaki mutlu ve sıkıntılı deneyimlerinin sadece kendine özgü olmadığının, mutlu, başarılı olma ya da olmamanın tüm bireylerin yaşayabileceği deneyimler olduğunu farkında olan bireydir (Neff, 2003). Yapılan diğer araştırmaya göre mutlulukta bilişsel farkındalığın rolü incelenmiş, mutluluk ile bilişsel farkındalık arasında pozitif yönlü ilişki olduğu belirlenmiştir. Pozitif duygusallık, hoş yaşantılar, yaşam doyumu, iyimserlik gibi mutluluk boyutlarının ta- 
mamıyla pozitif ilişkilidir. Yapılan farkındalık çalışmalarının duygu durum bozuklukları ve streste düşmeyi sağladığı belirlenmiştir (Brown ve Ryan, 2003). Sarıçam'ın (2015) 290 üniversite öğrencisi üzerinde algılanan sıkıntının bilişsel farkındalık ve mutluluk arasındaki aracılık rolünü incelemek için yapılan araştırmaya göre bilişsel farkındalık ile mutluluk arasında negatif yönlü ilişki bulunmuştur. Yani bilişsel farkındalık düzeyi yüksek olan bireylerin mutluluk düzeylerinin düştüğü belirtilmiştir. Dos'un (2014) üniversite öğrencileri üzerinde yaptığı araştırmada bilişsel farkındalığın öznel mutluluk üzerinde pozitif etkisi olduğu ve varyansın \% 2'sini açıkladığı belirlenmiştir. Bilişsel farkındalığın mutluluğu yordayacağı hipotezi ile yapılan bir diğer çalışmada, bilişsel farkındalığın mutluluğu pozitif yordadığ dalık becerileri olan izleme, değerlendirme, hedef belirleme, planlama ve strateji belirleme gibi hedefe yönelik içsel motivasyonla mutluluğu artıracağı belirtilmiştir (Kiaei ve Reio, 2014). Öz düzenleme becerilerinin lise öğrencilerinde mutluluğa etkisini inceleyen bir araştırmada, 15 deney 15 kontrol grubu (kız öğrenci) seçilmiş ve araştırma sonucunda öz düzenleme sürecinin parçası olan bilişsel farkındalık stratejilerinin kazandırılmasının öznel mutluluğu artırdığı belirlenmiştir (Mousavi ve Moghtader, 2015). Diğer bir çalışma olan, Sadeghi ve Mohammadi'nin (2017) 250 kişilik çalışma grubu ile yaptıkları araştırmada bilişsel farkındalığın öznel mutluluğu yordadığı ortaya konmuştur. Bilişsel farkındalık ve öznel mutluluk arasında pozitif yönlü bir ilişki belirlenmiştir. Bilişsel farkındalık becerileri yüksek olan birey olumlu, olumsuz yaşam durumları ile etkileşimde dengeyi sağlayan kişidir. Tahran üniversitesinde 100 öğrenci üzerinde yapılan araştırmada mutluluk, bilişsel farkındalık ve akademik başarı arasında pozitif yönlü ilişki olduğu ortaya konmuştur. Bilişsel farkındalık becerileri yüksek olan bireyler, çevreleri konusunda farkındalık sahibi olmaları dolayısıyla öz-yeterlikleri ve öz saygıları yüksektir ve diğer bireylere göre daha mutludurlar (SHoaakazemi, Javid, Keramati ve Tazekand, 2013). Mayor'un (2013) yaptığı araştırmaya göre bilişsel farkındalığın negatif düşüncelerin farkındalığı olduğu durumlarda mutluluğu negatif yordadığı, pozitif düşüncelerin farkındalığı olduğu durumlarda mutluluğu pozitif yordadığı ortaya konmuştur.

Araştırmanın üçüncü bulgusunda öğretmen adaylarında öznel mutluluk ve sıkıntıyı tolere etme arasındaki ilişkide sıkıntıyı tolere etmenin 
öznel mutluluğu etkilediği, ikisi arasındaki ilişkinin pozitif yönde olduğu belirlenmiştir. Yani sıkıntıyı tolere etme düzeyi yüksek bireyin öznel mutluluğunun da yükseleceği ortaya konmuştur. Alanyazına bakıldığında doğrudan sıkıntıyı tolere etme ile öznel mutluluk arasındaki ilişkiyi araştıran bir çalışmaya rastlanmamıştır. Sıkıntıyı tolere etmenin özellikle davranış bozuklukları tedavisinde teorik önemi artmış ve sıkıntıyı tolere etme düzeyini artırmaya yönelik tedaviler geliştirilmektedir (Vujanovic, Marshall- Berenz ve Zvolensky, 2011). Alver, Dilekmen ve Ada'nın (2010) yaptıkları çalışmalarda öznel mutluluğu yüksek olan bireylerin diğerlerine göre somatizasyon, obsesif-kompulsif bozukluk, kişilerarası duyarlılık, depresyon, anksiyete bozukluğu, fobik anksiyete, paranoid düşünceler ve psikotisizmin daha düşük seviyede olduğu belirlenmiştir. Sarıçam'ın (2015) çalışmasındaki bulguda algılanan sıkıntı ile mutluluk negatif yönde ilişkili bulunmuştur. Sıkıntıyı tolere etme duygu düzenlemedir. Duygu düzenlemesi ise yoğun duygu uyaranları ile başa çıkabilme becerisidir (Amstadter vd., 2012). Yapılan çalışmada duygu düzenlemesinin ve stres durumları ile başa çıkma yollarının mutluluğu pozitif yordadığı ortaya konmuştur (Özbay, Palancı, Kandemir ve Çakır, 2012). Şencan'ın (2015) üniversite öğrencileri üzerinde yaptığı çalışmada bu araştırma sonuçlarına paralel bulunan sonuçlara göre sıkıntıyı tolere etmenin mutlulukla pozitif yönde ilişkisi olduğu bulunmuştur. Diğer bir çalışmada sıkıntı durumuyla baş etmede yapılan duygu düzenlemede yeniden değerlendirmenin mutluluk düzeyini artırdığı fakat duyguları bastırmanın mutluluğu azalttığı belirtilmiştir. Yeniden değerlendirmede bulunan bireyler hem olumlu hem olumsuz duyguların diğerleri ile paylaşma ve sosyal ilişkilerde daha yakın, değer verdikleri ilişkiler içerisindedirler. Baskılamada bulunan birey duygularını maskeleyerek baş etme yolunu seçerler ve baskılama nedeniyle olumlu duyguları daha az fark etme ve ifade edememe durumuyla karşı karşıya bırakır (Gross ve John, 2003). Sıkıntılı yaşam olayları ile etkili baş etme olarak tanımlanan öğrenilmiş güçlülüğün öznel mutluluğun anlamlı bir yordayıcısı olduğu, öğrenilmiş güçlülüğü yüksek olan bireyin öznel mutluluğunun da yüksek olacağı belirtilmiştir (Cenkseven ve Akbaş, 2016). Öğrenilmiş güçlülük yaşanan sıkıntılara karşı etkin başa çıkma yolları üretme dağarcığı olarak ifade edilmiştir (Dağ, 1992). Öğrenilmiş güçlükte birey duygusal ve fiziksel tepkilerle başa çıkmada öz yönergelerini kullanır, planlama yapar, 
problemi tanılar, seçenekleri değerlendirerek sonuçları tahmin eder, anlık hazzı erteler ve içsel durumları bireyin kendisinin çözümleyebileceğine inanır (Dağ, 1991). Öğrenilmiş güçlülük düzeyi yüksek bireyler sıkıntı durumlarında çaresizliğe düşmeden, çözüm üretici düşünce ve davranışları geliştirerek, yaşam kalitelerini artırabilirler (Coşkun, 2008).

\section{Sonuç}

1. Öğretmen adaylarında bilişsel farkındalık düzeyinin sıkıntıyı tolere etmeyi yordadığı, bilişsel farkındalık düzeyleri ile sıkıntıyı tolere etme arasında pozitif yönlü doğrusal ilişki olduğu bulunmuştur. Yani öğretmen adaylarının bilişsel farkındalık düzeylerinin artmasıyla sıkıntıyı tolere etme düzeylerinde artış olacağı ortaya koyulmuştur.

2. Öznel mutluluğu etkileyen en önemli değişkenin sıkntıyı tolere etme olduğu belirlenmiştir. Öğretmen adaylarının sıkıntıyı tolere etme düzeylerinin öznel mutluluk düzeylerini yordadığı ve aralarında pozitif yönlü doğrusal bir ilişki bulunduğu ortaya konmuştur. Diğer bir deyişle öğretmen adaylarının sıkıntıyı tolere etme düzeyleri arttıkça öznel mutluluk düzeylerinin artacağı ortaya konmuştur.

3. Öznel mutluluğu etkileyen ikinci değişkenin bilişsel farkındalık olduğu belirlenmiştir. Öğretmen adaylarının bilişsel farkındalık düzeylerinin öznel mutluluk düzeylerini pozitif yönlü yordadığı ve aralarında doğrusal bir ilişki olduğu bulunmuştur. Diğer bir deyişle öğretmen adaylarının bilişsel farkındalık düzeyleri arttıkça öznel mutluluk düzeylerinin artacağı ortaya konmuştur.

\section{Öneriler}

Ulaşılan sonuçlar göz önünde bulundurularak aşağıdaki öneriler geliştirilebilir.

1. Bu araştırmanın çalışma grubu İstanbul ilindeki üniversite öğrencilerinden oluşmaktadır. Gelecekte yapılacak olan çalışmalarda farklı illerdeki üniversitelerden çalışma grupları ile ya da illerin tamamındaki üniversitelerde çalışmanın yapılmasının araştırma sonuçlarının genellenebilmesine katkı sağlayabileceği düşünülmektedir.

2. Bu araştırmanın çalışma grubu eğitim fakültesi öğrencilerinden oluşmaktadır. Araştırmanın diğer bölüm ve fakültelerdeki öğrencilerle 
tekrarlanmasının araştırmanın genellenebilmesine katkı sağlayabileceği için faydalı olabileceği düşünülmektedir.

3. Ülkemizde bilişsel farkındalık ve öznel mutluluk kavramları ile ilgili yapılan araştırmalar nispeten yaygın olsa da sıkıntıyı tolere etme kavramı ile ilgili çalışmalar oldukça sınırlıdır. Sıkıntıyı tolere etme ile ilgili yapılacak yeni çalışmalar kavramın teorik yapısının daha iyi anlaşılmasını sağlayabileceği düşünülmektedir.

4. Bu araştırmadaki çalışma grubu 18-25 yaş arası eğitim fakültesi öğrencilerinden oluşmaktadır. Araştırmadan elde edilen bulguların diğer yaş gruplarına genellenmesi mümkün değildir. Benzer çalışmaların diğer yaş gruplarına da yapılması araştırma konusu ile ilgili daha kapsamlı bilgi sahibi olunmasına katkı sağlayacağı düşünülmektedir.

5. Bu araştırmada bilişsel farkındalık, sıkıntıyı tolere etme ve öznel mutluluk arasındaki ilişkiler incelenmiştir. Yapılacak olan benzer diğer çalışmalarda ebeveyn eğitim durumu, medeni durum, sosyoekonomik düzey vb. değişkenler açısından incelenmesinin alan yazına katkı sağlayacağ1 düşünülmektedir.

6. Bu araştırmada bilişsel farkındalık, sıkıntıyı tolere etme ve öznel mutluluk arasındaki yordayıcı ilişkiler incelenmiştir. Yapılacak olan diğer çalışmalarda kavramların başarı düzeyi, cinsiyet, gelir düzeyi değişkenleri ile ilişkisi ve bu ilişkinin boyutunun incelenmesinin alan yazına katkı sağlayacağ 1 düşünülmektedir.

7. Bilişsel farkındalık, öznel mutluluk ve sıkıntıyı tolere etme hakkında yapılan araştırmalar çoğunlukla nicel çalışmalar olup var olan durumu ve durum değişimini ortaya koymaktadır. Ancak bu değişimin nasıl olduğu nicel çalışmalarda belirsiz kalmaktadır. Bu belirsizliğe 1şık tutması açısından araştırmacıların bu kavramlarla ilgili nitel çalışmalara yönelmesi isabetli olacaktır.

8. Bu araştırmada veriler yalnızca öz bildirime dayalı ölçme araçları aracılığıyla toplanmıştır. Bu durum bulguların daha ayrıntılı olarak ele alınmasına olanak sağlamamıştır. Yapılacak olan çalışmalarda gözlem ya da yaşantı örnekleme gibi farklı yöntemlerin benimsendiği araştırmalar daha fazla bulgu edinilebilmesine olanak sağlayabilir. Ayrıca çalışma grubundaki bireylerin çevrelerinden elde edilebilecek bilgilerin dikkate alınması ile daha güvenilir bulgular sağlanabilir. 


\title{
EXTENDED ABSTRACT
}

\section{The Predictive Relationship Between Cognitive Awareness Levels Subjective Happiness Distress Tolerance in Teacher Condidates}

\author{
Bülent Dilmaç - Mustafa Yılmaz \\ Necmettin Erbakan University - Ministry of National Education
}

The aim of this study is to examine the predictive relationships among cognitive awareness levels, subjective happiness and distress tolerance teacher candidates.

In the study, a structural equation modeling analysis was carried out in order to determine the relations between cognitive awareness, distress tolerance and subjective happiness in teacher candidates and the structural equality model of relations among these variables. The scales are composed of prospective teachers from various universities in Istanbul during the 2017-2018 education period. Of the 529 participants, 139 are male and 390 are female participants. The "distress tolerance scale" of Akın, Akça and Gülşen (2015) and "metacognition scale-30" of Tosun and Irak (2008) and "subjective happiness scale" of Doğan and Totan (2013) were used in the study. Amos 19 program was used in analysis of the data. Percentage and frequency calculations of collected data were also performed with the SPSS 18 packet program.

\section{Method}

In this study, which has a quantitative research paradigm, it is aimed to determine teacher candidates' cognitive awareness levels, distress tolerance and to determine the relationships between subjective happiness and to test the relationships between these variables with structural equation model.

For this purpose, the research was carried out according to the relational screening model, which is a sub-type of the general screening model. 
General screening models are screening studies in order to reach a general judgment about the universe on a group of samples or samples taken from the universe or the universe. General screening models allow individual or relational scans (Karasar, 2015). Relational screening models are research models aiming to determine whether or not the change between two or more variables coexist or not (Karasar, 2015).

\section{Result}

1. According to the findings obtained from the research; It was seen that the levels of cognitive awareness of candidate teachers predicts distress tolerance, and there is a positive linear relationship between cognitive awareness and distress tolerance. In other words, it was revealed that the level of students' ability to distress tolerance increases with the increase in cognitive awareness levels of the prospective teachers.

2. It was determined that the most important variable affecting subjective happiness was distress tolerance. It was revealed that the level of candidates teachers' distress tolerance predicts the levels of subjective happiness and there is a positive linear relationship between them. In other words, it was revealed that the level of subjective happiness would increase as the level of distress tolerance of teacher candidates increases.

3. The second variable affecting subjective happiness is cognitive awareness. It was found that the level of cognitive awarenesses of candidate teachers predicts the level of subjective happiness positively and that there is a linear relationship between them. In other words, it is revealed that the levels of subjective happiness will increase as the levels of cognitive awareness increase.

\section{Suggestions}

Considering the results achieved, the following suggestions can be developed.

1. The study group of this research consists of university students in Istanbul. In future studies, it is thought that conducting the study 
in universities in different provinces or in universities in all provinces may contribute to generalization of research results.

2. The study group of this research consists of the students of the faculty of education. It is thought that repetition of the study with the students in other departments and faculties may be useful as it may contribute to the generalization of the research.

3. Although the researches on cognitive awareness and subjective happiness are relatively common in our country, studies on the concept of distress tolerance are quite limited. New studies on distress tolerance is expected to provide a better understanding of the theoretical structure of the concept.

4. The study group consists of 18-25 years old faculty of education. It is not possible to generalize the findings of the research to other age groups. It is thought that similar studies on other age groups will contribute a more comprehensive knowledge about the research topic.

5. In this study, the relationship between cognitive awareness, distress tolerance and subjective happiness were investigated. In other similar studies to be done, it is thought that examining in terms of parental educational status, marital status and socioeconomic level will contribute to the literature.

6. In this research, the predictive relationships among cognitive awareness, distress tolerance and subjective happiness were examined. In other studies, all the concepts, level of success, gender, relationship with income level variables and the examination of the extent of this relationship are thought to contribute to the literature.

7. Studies on cognitive awareness, subjective happiness and distress tolerance are mostly quantitative studies and reveal the current situation and change of situation. However, this change is uncertain in quantitative studies. In order to shed light on this uncertainty, it would be appropriate for researchers to focus on qualitative studies about these concepts.

8. In this study, data were collected only by means of self-reporting instruments. This did not allow for further consideration of the findings. Studies in which different methods such as observation 
or experience sampling are adopted may allow more findings to be obtained. In addition, more reliable findings can be obtained by taking into account the information that can be obtained from the individuals in the study group.

\section{Kaynakça / References}

Abacı, R. (2010a). Yaşamın kalitelendirilmesi. İstanbul: Bakanlar Matbaacilik.

Abacı, R. (2010b). Akıl karı olmayan işler. İstanbul: Bakanlar Medya.

Akın, A., Akça, M. Ş. ve Gülşen, M. (2015). Sıkıntıyı tolere etme ölçeği türkçe formu: Geçerlik ve güvenirlik çalışması. Kastamonu Eğitim Dergisi, 23(2), 619-630.

Aktamış, H. ve Uça, S. (2010). Motivasyonel, bilişsel ve bilişüstü yeterlilikler ölçeği'nin Türkçeye uyarlanması. Ilköğretim Online, 9(3), 980989.

Alisinanoğlu, F. (2002). Gençlik dönemi özellikleri ve genç anne-baba iletişimi. Ĕğitim ve Bilim, 27(123), 62-63.

Alver, B., Dilekmen, M. ve Ada, Ş. (2016). Üniversite öğrencilerinin bazı öznel algilamalarına göre psikolojik belirtileri. Türk Psikolojik Danışma ve Rehberlik Dergisi, 4(33), 13-23.

Amstadter, A. B., Daughters, S. B., MacPherson, L., Reynolds, E. K., Danielson, C. K., Wang, F., Potenza, M., C., Gelernter, J. ve Lejuez, C. W. (2012). Genetic associations with performance on a behavioral measure of distress intolerance. Journal Of Psychiatric Research, 46(1), 87-94.

Atak, H. ve Çok, F. (2010). İnsan yaşamında yeni bir dönem: Beliren yetişkinlik. Çocuk ve Gençlik Ruh Sağlı̆̆ı Dergisi, 17(1), 39-50.

Atkinson, R. L., Atkinson, R.C., Smith, E.E., Bem, D.J. \& Nolen-Hoeksema, S. (2010). Psikolojiye giriş. Yavuz Alogan (Çev.), İstanbul: Arkadaş Yayınevi.

Azari, S., Khademi, A. ve Esmali, A. (2013). The effectiveness of metacognitive therapy in distress tolerance in adolescent boys. International Journal of Psychology and Behavioral Research, 1(1), 291-303. 
Bollen, K. A. (1989). A newincremental fit indexfor general structural equation models. Sociological Methodsand Research, 17 (3), 303-316.

Broderick, P. C. ve Frank, J. L. (2014). Learning to breathe: An intervention to foster mindfulness in adolescence. New Directions for Student Leadership, (142), 31-44.

Brown, R. A., Lejuez, C. W., Kahler, C. W., Strong, D. R. ve Zvolensky, M. J. (2005). Distress tolerance and early smoking lapse. Clinical Psychology Review, 25(6), 713-733.

Brown, K. W. ve Ryan, R. M. (2003). The benefits of being present: mindfulness and its role in psychological well-being. Journal of Personality and social psychology, 84(4), 822-848.

Browne, M. W. ve Cudeck, R. (1993). Alternative ways of assessing model fit. Sage Focus Editions, 154, 136-162.

Burger, J. M. (2006). Kişilik. İnan Deniz Erguvan Sarığlu (Çev.), İstanbul: Kaknüs Yayınları.

Byrne, B. M. (2010). Structural equation modeling with AMOS: Basic concepts, applications, andprogramming (2nd ed.). New York: Taylor and Francis.

Cenkseven, F. ve Akbaş, T. (2016). Üniversite öğrencilerinde öznel ve psikolojik iyi olmanın yordayıcılarının incelenmesi. Türk Psikolojik Danışma ve Rehberlik Dergisi, 3(27), 43-65.

Ceylan, T. M. (2012). Ortak benlik nörofelsefi temellendirme. İstanbul: Ayrıntılı Yayınları.

Costa, A. L. (1984). Mediating the metacognitive. Educational Leadership, 42(3), 57-62.

Coşkun, Y. (2008). Ortaöğretim öğrencilerinin aile içi ilişkilerinin, öğrenilmiş güçlülük düzeylerini yordama gücü. İnönü Üniversitesi Eğitim Fakültesi Dergisi, 9(16), 43-65.

Çatak, P. D. ve Ögel, K. (2010). Farkındalık temelli terapiler ve terapötik süreçler. Klinik Psikiyatri, 13, 85-91.

Dağ, İ. (1991). Rosenbaum'un öğrenilmiş güçlülük ölçeğinin üniversite öğrencileri için güvenirliği ve geçerliği. Türk Psikiyatri Dergisi, 2(4), 269-274.

Dağ, İ. (1992). Kontrol odağı, öğrenilmiş güçlülük ve psikopatoloji ilişkileri. Psikoloji Dergisi, 7(27), 1-9. 
Daughters, S. B., Ross, T. J., Bell, R. P., Yi, J. Y., Ryan, J. ve Stein, E. A. (2017). Distress tolerance among substance users is associated with functional connectivity between prefrontal regions during a distress tolerance task. Addiction Biology, 22(5), 1378-1390. doi:10.1111/adb.12396

Demir, Ö. ve Doğanay, A. (2010). Bilişsel koçluk yöntemiyle öğretilen bilişsel farkındalık stratejilerinin altıncı sınıf sosyal bilgiler dersinde bilişsel farkındalık becerilerine ve Kalıcılığa etkisi. Elementary Education Online, 9(1), 106-127.

Demir, Ö. ve Kaya, H. İ. (2015). Öğretmen adaylarının bilişsel farkındalık beceri düzeylerinin eleştirel düşünme durumları ile ilişkilerinin incelenmesi. Pegem Eğitim ve Öğretim Dergisi, 5(1), 35-68. http://dx.doi.org/10.14527/pegegog.2015.003

Deniz, M., Kesici, Ş. ve Sümer, A. S. (2008). The validity and reliability of the Turkish version of the Self-Compassion Scale. Social Behavior and Personality: An International Journal, 36(9), 1151-1160.

Diener, E. (1984). Subjective well-being. Psychological Bulletin, 95(3), 542575.

Doğan, A. (2013). Üstbiliş ve üstbilişe dayalı öğretim. Middle Eastern $\mathcal{E}$ African Journal of Educational Research, 3, 6-20.

Doğan, T.,ve Totan, T. (2013). Psychometric properties of Turkish version of the Subjective Happiness Scale. The Journal of Happiness $\mathcal{E}$ WellBeing, 1(1), 21-28.

Dos, B. (2014). The relationship between mobile phone use, metacognitive awareness and academic achievement. European Journal of Educational Research, 3(4), 192-200.

Gable, S. L. ve Haidt, J. (2005). What (and why) is positive psychology?. Review of general psychology, 9(2), 103-110.

Geçtan, E. (2002). Psikanaliz ve sonrası. İstanbul: Metis Yayınları.

Girgin, M. (2012). Pedagojik değerler. Ankara: Vize Yayıncilık.

Gross, J. J. (2013). Emotion regulation: taking stock and moving forward. Emotion, 13(3), 359-365.

Gross, J. J. ve John, O. P. (2003). Individual differences in two emotion regulation processes: implications for affect, relationships, and wellbeing. Journal of personality and social psychology, 85(2), 348-362. 
Hayes, A. M. ve Feldman, G. (2004). Clarifying the construct of mindfulness in the context of emotion regulation and the process of change in therapy. Clinical Psychology: Science and Practice, 11(3), 255-262.

$\mathrm{Hu}, \mathrm{L}$. T. ve Bentler, P. M. (1999). Cutoffcriteriafor fit indexes in covariancestructureanalysis: conventional criteria versus new alternatives. Structural Equation Modeling: A Multidisciplinary Journal, 6 (1), 1-55.

Karasar, N. (2015). Bilimsel araştırma yöntemi. Ankara: Nobel Yayınları.

Kiaei, Y. A. ve Reio Jr, T. G. (2014). Goal pursuit and eudaimonic wellbeing among university students: Metacognition as the mediator. Behavioral development bulletin, 19(4), 91-104.

Kline, R. B. (2011), Principle sand practice of structural equation modeling. New York: The Guilford Press.

Lyubomirsky, S. ve Lepper, H. S. (1999). A measure of subjective happiness: preliminary reliability and construct validation. Social Indicators Research, 46(2), 137-155.

Mayor, H. (2013) Beyond the negative: the role of positive metacognitions, metaemotions and maladaptive metacognitions in depression, anxiety and life satisfaction in individuals with vasculitis. MMU Psychology Journal, 135. http://e-space.mmu.ac.uk/id/eprint/576653

Mohammadkhani, S. (2013). The role of fusion beliefs and metacognitions in obsessive-compulsive symptoms in general population. Iranian Journal of Clinical Psychology (IJCP), 1(2), 29- 35.

Mousavi, A. ve Moghtader, L. (2015). The effect of self-regulation skills on self-efficacy and happiness of high-school students. Journal of Applied Environmental and Biological Sciences, 5(12S), 179-182.

Myers, D. G. ve Diener, E. (1995). Who is happy?. Psychological Science, 6(1), 10-19.

Neff, K. D. (2003). Self-compassion: an alternative conceptualization of a healthy attitude toward oneself. Self and Identity, 2, 81-101.

Nesse, R. M. (2000). Is depression an adaptation?. Archives of General Psychiatry, 57(1), 14-20.

Oturakçı, N. (2012). Divânü Lügati't Türk'te gerçek anlamlılık düzleminde betimleyici duygu göstergesi olarak mutluluk. Çukurova Üniversitesi Sosyal Bilimler Enstitüsü Dergisi, 21(2), 221-232. 
Özbay, Y., Palancı, M., Kandemir, M. ve Çakır, O. (2012). Üniversite öğrencilerinin öznel iyi oluşlarının duygusal düzenleme, mizah, sosyal öz-yeterlik ve başaçıkma davranışları ile yordanması. Türk Ĕ̆itim Bilimleri Dergisi, 10(2), 325-345.

Özen, Y. (2017). Farkında mıyız? (bilişsel farkındalık ile psikolojik iyi oluşun içrelleşmesi). Kesit Akademi Dergisi, 3(7), 167-189.

Ridley, D. S., Schutz, P. A., Glanz, R. S. ve Weinstein, C. E. (1992). Selfregulated learning: The interactive influence of metacognitive awareness and goal-setting. The journal of experimental education, 60(4), 293-306.

Roemer, L. ve Orsillo, S. M. (2003). Mindfulness: A promising intervention strategy in need of further study. Clinical psychology: Science and practice, 10(2), 172-178. doi: 10.1093/clipsy/bpg020

Sadeghi, M. J. ve Mohammadi, M. (2017). Role of emotional maturity, cognitive and metacognitive approach in predicting happiness in law enforcement officials of shiraz. Pharmacophore, 8(6S). e-1173407. http://www.pharmacophorejournal.com

Sarıçam, H. (2015). Metacognition and happiness: the mediating role of perceived stress. Studia Psychologica, 57(4), 271-283.

Saulsman, L. ve Nathan, P. (2012). Facing your feelings: Learning to tolerate distress. Perth, Western Australia: Centre for Clinical Interventions. http://www.cci.health.wa.gov.au/docs/Distress\%20Tolerance\%20Module\%201.pdf adresinden 27 Aralık 2018' de erişilmiştir.

Schraw, G. ve Moshman, D. (1995). Metacognitive theories. Educational psychology review, 7(4), 351-371.

Schumacker, R. E. ve Lomax, R. G. (2004). A beginner's guide to structural equation modelling. London: Lawrence Erlbaum Associates, Publishers.

Shin, D. C. ve Johnson, D. M. (1978). Avowed happiness as an overall assessment of the quality of life. Social indicators research, 5(4), 475492.

SHoaakazemi, M., Javid, M. M., Keramati, R. ve Tazekand, F. D. E. (2013). The relationship between happiness, meta-cognitive skills (selfregulation, problem-solving) and academic achievement of students in Tehran. Life Sci J, 10(4s), 452-457. 
Simons, J. S. ve Gaher, R. M. (2005). The Distress Tolerance Scale: Development and validation of a self-report measure. Motivation and Emotion, 29(2), 83-102.

Şencan, B. (2015). Bağlanma örüntüleri ve psikolojik iyilik hali arasındaki ilişkilerde duygusal şemalar, duygusal zorlanmaya tolerans ve kişilerarası beklentilerin rolü. (Yayımlanmamış Yüksek Lisans Tezi). Hacettepe Üniversitesi, Ankara.

Tanaka, J. S. ve Huba, G. J. (1985). A fit index for covariance structure models under arbitrary GLS estimation. British Journal of Mathematical and Statistical Psychology, 38(2), 197-201.

Tosun, A. ve Irak, M. (2008). Üstbiliş ölçeği-30'un Türkçe uyarlaması, geçerliği, güvenirliği, kayg1 ve obsesif-kompülsif belirtilerle ilişkisi. Türk Psikiyatri Dergisi, 19(1), 67-80.

Vann, A., Strodl, E. ve Anderson, E. (2013). Thinking about internal states, a qualitative investigation into metacognitions in women with eating disorders. Journal of eating disorders, 1(22), 1-11.

Vatan, S. (2016). Bilişsel davranışçı terapilerde üçüncü kuşak yaklaşımlar. Psikiyatride Güncel Yaklaşımlar, 8(3), 190-203. doi: 10.18863/pgy.238183

Veenhoven, R. (1994). Is happiness a trait?. Social indicators research, 32(2), 101-160.

Vujanovic, A. A., Marshall-Berenz, E. C. ve Zvolensky, M. J. (2011). Posttraumatic stress and alcohol use motives: A test of the incremental and mediating role of distress tolerance. Journal Of Cognitive Psychotherapy, 25(2), 130-141.

Yörükoğlu, A. (1990). Gençlik Çă̆ı Ruh Sağhlğ̆ı ve Ruhsal Sorunları. İstanbul: Özgür Yayın-Dağıtım.

Zvolensky, M. J., Leyro, T. M., Bernstein, A. ve Vujanovic, A. A. (2011). Historical Perspectives, Theory, And Measurement Of Distress Tolerance. Distress Tolerance: Theory, Research, And Clinical Applications. NewYork: Guilford Publications.

Wachs, K. ve Cordova, J. V. (2007). Mindful relating: exploring mindfulness and emotion repertoires in intimate relationships. Journal of Marital and Family therapy, 33(4), 464-481. 
Wells, A. ve Cartwright-Hatton, S. (2004). A short form of the metacognitions questionnaire: properties of the MCQ-30. Behaviour Research and Therapy, 42(4), 385-396.

Wilson, J. (2001). Methodological Difficulties of Assessing Metacognition: A New Approach", Australian Association for Research in Education Conference, 2 - 6 December 2001, Fremantle-Australia. https://www.aare.edu.au/data/publications/2001/wil01001.pdf 30 Ekim 2018'de erişilmiştir.

\section{Kaynakça Bilgisi / Citation Information}

Yılmaz, M. ve Dilmaç, B. (2019). Öğretmen adaylarında bilişsel farkındalık düzeyleri, öznel mutluluk ve sıkıntıyı tolere etme arasındaki yordayıcı ilişkiler. OPUS-Uluslararası Toplum Araştırmaları Dergisi, 10(17), 1125-1155. DOI: 10.26466/opus.520293 